\title{
Effect of renal impairment on the pharmacokinetics of prucalopride: a single- dose open-label Phase I study
}

This article was published in the following Dove Press journal:

Drug Design, Development and Therapy

17 December 2012

Number of times this article has been viewed

\author{
William B Smith' \\ Erik Mannaert ${ }^{2}$ \\ Tom Verhaeghe ${ }^{2}$ \\ René Kerstens ${ }^{3}$ \\ Lieve Vandeplassche ${ }^{3}$ \\ Vera Van de Velde ${ }^{4}$ \\ 'Volunteer Research Group and \\ New Orleans Center for Clinical \\ Research, The University of \\ Tennessee Medical Center, Knoxville, \\ TN, USA; ${ }^{2}$ Janssen Research and \\ Development, a division of Janssen \\ Pharmaceutica NV, Beerse, Belgium; \\ ${ }^{3}$ Shire-Movetis NV, Turnhout, \\ Belgium; ${ }^{4}$ Independent Consultant \\ Clinical Pharmacokinetics, Princeton, \\ NJ, USA
}

Objective: To evaluate the pharmacokinetics of prucalopride in individuals with renal impairment (RI).

Methods: This open-label Phase I study (ClinicalTrials.gov identifier: NCT01674192) enrolled men and women aged 18-75 years who were classified by renal function: normal renal function (creatinine clearance $\left.\geq 80 \mathrm{~mL} / \mathrm{min} / 1.73 \mathrm{~m}^{2}\right)$, mild RI $\left(50-79 \mathrm{~mL} / \mathrm{min} / 1.73 \mathrm{~m}^{2}\right)$, moderate RI $\left(25-49 \mathrm{~mL} / \mathrm{min} / 1.73 \mathrm{~m}^{2}\right)$, and severe RI $\left(\leq 24 \mathrm{~mL} / \mathrm{min} / 1.73 \mathrm{~m}^{2}\right)$. All received a single oral dose of prucalopride $2 \mathrm{mg}$.

Results: Thirty-four individuals (normal renal function: 10; mild RI: 8; moderate RI: 7; severe RI: 9) received prucalopride. In all groups, maximum plasma concentration was reached within 2-4 hours. There was no significant difference in exposure (area under the plasma concentrationtime curve from time zero to infinity) between participants with mild RI and those with normal renal function. However, area under the plasma concentration-time curve from time zero to infinity values were 1.5 - and 2.3 -fold higher $(P=0.002$ and $P<0.001)$ in patients with moderate RI and severe RI, respectively, than in those with normal renal function. The proportion of total body clearance accounted for by renal clearance was significantly reduced in those with RI.

Conclusion: Clinically meaningful reductions in renal clearance were seen in participants with severe RI, which supports a decrease from the standard dose of prucalopride $2 \mathrm{mg}$ daily to $1 \mathrm{mg}$ daily in these individuals.

Keywords: renal impairment, pharmacokinetics, prucalopride, safety

\section{Introduction}

Prucalopride (Resolor ${ }^{\circledR}$, prucalopride succinate tablets; Shire-Movetis NV, Turnhout, Belgium) is a dihydrobenzofuran-carboxamide derivative with strong gastrointestinal prokinetic activity. ${ }^{1,2}$ It is a selective, high-affinity 5-hydroxytryptamine type $4\left(5-\mathrm{HT}_{4}\right)$ receptor agonist and is indicated for the symptomatic treatment of chronic constipation in women for whom laxatives fail to provide adequate relief. The recommended dose in adults is $2 \mathrm{mg}$ once daily.

The efficacy of prucalopride has been demonstrated in three identical, pivotal, Phase III trials that enrolled both men and women. ${ }^{3-5}$ These studies have shown that treatment with prucalopride $2 \mathrm{mg}$ once daily for 12 weeks increases the frequency of spontaneous complete bowel movements in adults with chronic constipation. Prucalopride treatment is also associated with improvements in patients' satisfaction with therapy and bowel function and in their perception of constipation severity and constipation-related quality of life. Prucalopride is well tolerated, even at twice the normal recommended dose. The most common adverse events (AEs) are headache,
Correspondence: Lieve Vandeplassche Shire-Movetis NV, Veedijk 58 (I004), 2300 Turnhout, Belgium

Tel +32 I4 404355

Email Ivandeplassche@shire.com 
nausea, abdominal pain, and diarrhea, which tend to be transient and mild or moderate in intensity.

The pharmacokinetic profile of prucalopride in healthy individuals has been studied extensively. ${ }^{1,2,6}$ Studies show that prucalopride is well absorbed, with maximum plasma concentration $\left(\mathrm{C}_{\max }\right)$ being reached in approximately 2 hours. Prucalopride undergoes only limited metabolism, with the major metabolite accounting for less than $4 \%$ of the recovered dose. Renal excretion is the most important route of elimination for prucalopride; approximately $60 \%$ is excreted unchanged in urine and about $6 \%$ in feces. ${ }^{1,2,6}$ Prucalopride displays linear kinetics and has a terminal half-life $\left(\mathrm{t}_{1 / 2}\right)$ of approximately 1 day. ${ }^{1,2,6}$

Given that prucalopride is cleared predominantly via renal excretion, it is important to study the pharmacokinetics of prucalopride in individuals with impaired renal function. Therefore, the aim of this study was to compare the pharmacokinetics, safety, and tolerability of a single oral dose of prucalopride $2 \mathrm{mg}$ in patients with various degrees of renal impairment and in healthy individuals with normal renal function. Although prucalopride is currently approved for use only in women, both men and women were enrolled in this study to enable the results to be applicable to potential future use in men.

\section{Methods}

\section{Study design}

This open-label Phase I study (ClinicalTrials.gov identifier: NCT01674192) was conducted in a single center (New Orleans Center for Clinical Research, New Orleans, LA) from July 23, 1997 to August 8, 1999. ${ }^{7}$ The study was conducted in accordance with the Declaration of Helsinki and International Conference on Harmonization Good Clinical Practice guideline, and was approved by the relevant independent ethics committees. ${ }^{8,9}$ All participants provided written informed consent before screening.

\section{Participants}

Men and women were eligible for inclusion in the study if they were aged 18-75 years and did not smoke more than half a pack of cigarettes, two cigars, or two pipes daily. Women had to be of non-childbearing potential (defined as having had a total hysterectomy with ovaries intact, having undergone bilateral tubal ligation at least 6 months before study entry, or being post-menopausal for at least 2 years). In addition, participants with normal renal function had to have no clinically significant abnormalities on physical examination and in laboratory investigation results in the 2 weeks before dosing, and no clinically significant abnormalities observed on the electrocardiogram (ECG) at screening.
Screening evaluations were performed 2 weeks before the start of the study, during which time eligible individuals were classified into one of four groups by renal function: normal renal function (creatinine clearance $\left[\mathrm{CL}_{\mathrm{CR}}\right], \geq 80 \mathrm{~mL} / \mathrm{min} / 1.73 \mathrm{~m}^{2}$ ), mild renal impairment $\left(\mathrm{CL}_{\mathrm{CR}}, 50-79 \mathrm{~mL} / \mathrm{min} / 1.73 \mathrm{~m}^{2}\right)$, moderate renal impairment $\left(\mathrm{CL}_{\mathrm{CR}}, 25-49 \mathrm{~mL} / \mathrm{min} / 1.73 \mathrm{~m}^{2}\right)$ or severe renal impairment $\left(\mathrm{CL}_{\mathrm{CR}}, \leq 24 \mathrm{~mL} / \mathrm{min} / 1.73 \mathrm{~m}^{2}\right)$. Severity of renal impairment was required to be stable, which was defined as: the value of 1/creatinine/time being within two standard deviations, if known; or the $\mathrm{CL}_{\mathrm{CR}}$ not having changed by more than $20 \%$ from the last test, which had been performed in the 6 months before study entry. Patients with mild renal impairment were to be enrolled first, followed by those with moderate and severe renal impairment, and finally by the participants with normal renal function. Individuals with normal renal function were matched for age (within $10 \%$ of the mean age), sex, height, and weight (within $30 \%$ of the mean height and weight) to those with renal impairment.

Key exclusion criteria were: a history of hypersensitivity to prucalopride, related prokinetic compounds, or the inactive ingredients in the prucalopride capsule; use of another investigational drug in the 30 days before enrollment; a history of significant blood loss or donation of blood or plasma $(500 \mathrm{~mL})$ within the past 30 days; gastrointestinal surgery in the 3 months before enrollment; previous major gastrointestinal surgery with the potential to compromise drug absorption or metabolism; use of anticoagulant therapy in the 3 months before the study; use of a liquid-protein diet in the 30 days before the study; and use of cisapride in the 60 days before the study or any other prokinetic in the 2 weeks before the study. Individuals were also excluded if they had: a positive test result for hepatitis B surface antigen, human immunodeficiency virus infection, or rapid plasma reagin; urinary incontinence; known significant bleeding diathesis that could preclude multiple venepuncture; or evidence of drug or alcohol abuse. Women who were pregnant or breastfeeding were excluded. Individuals were required to discontinue all concomitant therapy that might potentially interfere with the study medication.

In addition, participants with normal renal function were excluded if they had used any medications (except acetaminophen/paracetamol for headache) in the 7 days before the study or needed to use medication during the study. Additional exclusion criteria for patients with renal impairment were: a history of uric acid stone disease, uricosuria, or gout; current hyperuricemia (serum uric acid $>10 \mathrm{mg} / \mathrm{dL}$ ); uncontrolled type 1 or 2 diabetes mellitus; 
renal transplant, systemic lupus erythematosus, or renal carcinoma; potassium, magnesium, and/or calcium outside the normal limits; moderate-to-severe uncontrolled hypertension (diastolic blood pressure $\geq 105 \mathrm{mmHg}$ and/or systolic blood pressure $\geq 180 \mathrm{mmHg}$ ); or current use of any of the calcium-channel blockers bepridil, diltiazem, isradipine, nicardipine, nimodipine, and verapamil.

\section{Treatments}

All participants received a single oral dose of prucalopride $2 \mathrm{mg}$, formulated as a capsule (prucalopride hydrochloride equivalent to prucalopride $2 \mathrm{mg}$ base), which was ingested with $180 \mathrm{~mL}$ of non-carbonated water. Prucalopride was administered at the clinic on day 1 at approximately $8 \mathrm{am}$, after an overnight fast of at least 10 hours. Participants consumed a standard breakfast 2 hours after the administration of prucalopride. Food consumption and fluid intake were standardized and carefully monitored.

\section{Assessments}

A $10 \mathrm{~mL}$ blood sample was collected before administration of prucalopride for in vitro determination of plasma protein binding (PPB) of prucalopride. Serial venous blood samples $(7 \mathrm{~mL})$ were taken immediately before prucalopride administration and at $0.5,1$ hour, and 2, 2.5, 3, 3.5, 4, 5, 6, 8, 10, 12 , $16,24,30,36,48,72,96$, and 120 hours after administration. Blood samples were collected in heparinized tubes, which were inverted gently two or three times and then centrifuged (3000 rpm for 10 minutes) within 1 hour of collection. The separated plasma was pipetted into tubes and the samples were frozen and stored at or below $-20^{\circ} \mathrm{C}$ until assayed. Complete urinary output was collected over the 8 hours before prucalopride administration and then at intervals of $0-6,6-12,12-24$, 24-48, 48-72, 72-96, and 96-120 hours after administration. After thorough mixing of each collection, volume and $\mathrm{pH}$ were measured then $20 \mathrm{~mL}$ aliquots of each collection were frozen and stored at $-20^{\circ} \mathrm{C}$ until assayed.

\section{Analytical methodology}

Plasma and urine concentrations of prucalopride were determined using a sensitive, specific radioimmunoassay (RIA). Antiserum was obtained through immunization of a female New Zealand white rabbit. This antiserum was diluted in $2 \%$ bovine serum albumin (BSA), lyophilized, and stored at $4{ }^{\circ} \mathrm{C}$ until use.

In the plasma assay procedure, $0.55 \mathrm{~mL} 2 \%$ BSA solution, $0.1 \mathrm{~mL}$ diluted antiserum, and $0.1 \mathrm{~mL}$ aliquots of tritiated $\left({ }^{3} \mathrm{H}\right)$ prucalopride (63.5 Ci/mmol; 25,000 dpm dilution in 2\% BSA) were added to $0.1 \mathrm{~mL}$ aliquots of plasma. The samples were incubated for 2 hours under continuous rotation at room temperature in the dark. Bound and free prucalopride were separated by selective adsorption of the free ligand using $0.2 \mathrm{~mL}$ of a $2 \%$ dextran-coated charcoal suspension. The charcoal was precipitated by centrifugation, and the supernatants (containing the antibody-bound prucalopride fractions) were aspirated and quantitatively transferred to counting vials. After mixing with $4 \mathrm{~mL}$ of a scintillation cocktail (Ultima-Flo ${ }^{\mathrm{TM}} \mathrm{AP}$; PerkinElmer, Waltham, MA), the radioactivity was counted for 2 minutes in a liquid scintillation analyzer (Packard Tri-Carb ${ }^{\circledR}$ 2100 TR; Packard Instrument Company, Downers, IL). With every batch of study samples, a series of calibration standards spiked in blank human plasma in the range $0.10-10.0 \mathrm{ng} / \mathrm{mL}$ was processed in duplicate. Every batch contained quality control samples at the low $(0.32 \mathrm{ng} / \mathrm{mL})$, medium $(1.62 \mathrm{ng} / \mathrm{mL})$, and high $(7.13 \mathrm{ng} / \mathrm{mL})$ levels in duplicate for batch acceptance. Four-parameter logistic curve fitting (on the average values of the calibration standards) was used. Overall accuracy from the quality control samples ranged from $95.7 \%$ to $104.0 \%$, and overall precision ranged from $5.1 \%$ to $11.8 \%$.

Urine samples were diluted $1 / 100$ in $2 \%$ BSA, and $100 \mu \mathrm{L}$ aliquots of these dilutions were subsequently processed as described above for the plasma samples, which shifted the concentration range to $10-1000 \mathrm{ng} / \mathrm{mL}$. Duplicate quality control samples at $63.5 \mathrm{ng} / \mathrm{mL}, 397 \mathrm{ng} / \mathrm{mL}$, and $620 \mathrm{ng} / \mathrm{mL}$ were processed for batch acceptance. This resulted in an overall accuracy of $102.2 \%-108.9 \%$ and an overall precision of $4.9 \%-6.8 \%$. The specificity of the RIA was demonstrated through cross-validation with a liquid chromatographytandem mass spectrometry (LC-MS/MS) assay by analyzing dosed participant samples using both assays. This confirmed the absence of cross-reactivity by circulating metabolites.

The stability of prucalopride in human blood was demonstrated for up to 72 hours at $4^{\circ} \mathrm{C}, 24$ hours at room temperature, and 2 hours at $37^{\circ} \mathrm{C}$. In plasma, stability of the analyte was demonstrated after two freeze-thaw cycles and after storage for 72 hours at room temperature and 825 days at $-20^{\circ} \mathrm{C}$.

The PPB of prucalopride was determined in the predose plasma sample collected on day 1 . The percentage of bound prucalopride was determined using a Dianorm ${ }^{\circledR}$ equilibrium dialyzer (Dianorm Geräte, Munich, Germany), which allowed free prucalopride to be separated from the bound fraction.

\section{Pharmacokinetic analyses}

The following pharmacokinetic parameters were determined with WinNonlin ${ }^{\circledR}$ Professional (v 3.0, Pharsight Corporation, 
Mountain View, CA) using non-compartmental methods: $\mathrm{C}_{\text {max }}$; time to $\mathrm{C}_{\text {max }}\left(\mathrm{t}_{\max }\right)$; area under the plasma concentrationtime curve from time zero to infinity $\left(\mathrm{AUC}_{\infty}\right.$; calculated as $\mathrm{AUC}_{\text {last }}+\mathrm{C}_{\text {last }} / \lambda$, where $\mathrm{C}_{\text {last }}$ is the last quantifiable plasma concentration and $\lambda_{\mathrm{z}}$ is the elimination rate constant determined by linear regression of the terminal points of the loglinear plasma concentration-time curve); terminal half-life $\left(\mathrm{t}_{1 / 2}\right.$; defined as $\left.0.693 / \lambda_{\mathrm{z}}\right)$; and apparent total body clearance $\left(\mathrm{CL} / \mathrm{F}\right.$, dose divided by $\left.\mathrm{AUC}_{\infty}\right)$. PPB, expressed as a percentage, was calculated as 100 minus the fraction of unbound prucalopride (the ratio of unbound prucalopride concentration to the total prucalopride concentration).

In addition, the following parameters were calculated from the concentrations of prucalopride in urine collected from 0 to 120 hours after dosing: the cumulative amount of prucalopride excreted in urine from time 0 to 120 hours $\left(\mathrm{Ae}_{120 \mathrm{~h}}\right.$; calculated by summation of the amounts excreted in the subsequent collection intervals), the renal clearance $\left(\mathrm{CL}_{\mathrm{R}}\right.$; calculated as $\mathrm{Ae}_{120 \mathrm{~h}}$ divided by $\mathrm{AUC}_{120 \mathrm{~h}}$ or $\mathrm{Ae}_{\text {last }}$ divided by $\left.\mathrm{AUC}_{\text {last }}\right)$, and the cumulative fraction of the dose excreted unchanged in urine from time 0 to 120 hours $\left(\mathrm{Fe}_{120 \mathrm{~h}}\right.$; calculated by summation of the fractions excreted in the subsequent collection intervals). Glomerular filtration rate of prucalopride $\left(\mathrm{CL}_{\mathrm{gfr}}\right.$; calculated as the fraction of unbound drug in plasma multiplied by $\mathrm{CL}_{\mathrm{CR}}$ ), active renal secretion rate $\left(\mathrm{CL}_{\text {act }}\right.$; calculated as the difference between $\mathrm{CL}_{\mathrm{R}}$ and $\left.\mathrm{CL}_{\mathrm{gfr}}\right)$, the fraction of renal clearance due to active renal secretion $\left(\mathrm{CL}_{\text {act }} / \mathrm{CL}_{\mathrm{R}}\right)$, the fraction of apparent total clearance due to active renal secretion $\left(\mathrm{CL}_{\text {act }} / \mathrm{CL} / \mathrm{F}\right)$, the fraction of renal clearance due to glomerular filtration $\left(\mathrm{CL}_{\mathrm{gfr}} / \mathrm{CL}_{\mathrm{R}}\right)$, and the fraction of apparent total clearance due to glomerular filtration rate $\left(\mathrm{CL}_{\mathrm{gfr}} / \mathrm{CL} / \mathrm{F}\right)$ were calculated from the parameters given.

\section{Safety}

Adverse Events (AEs) were reported spontaneously or after non-leading questioning. The severity of each $\mathrm{AE}$ and the relationship of each $\mathrm{AE}$ with the study drug were recorded. Vital signs were monitored pre-dose and at 12, 24, 36, 48, $60,72,96$, and 120 hours post-dose.

\section{Statistical analysis}

A formal sample size calculation was not performed; however, a target of eight participants per group was considered sufficient to evaluate clinically relevant effects of renal impairment on the pharmacokinetics and safety of prucalopride. Minor variations in this number (seven in the moderate group and nine in the severe group) were considered acceptable.
All statistical comparisons were performed using SAS software (v 9.2; SAS Institute, Cary, NC). All statistical inferences were based on two-sided tests with $\alpha=0.05$.

Descriptive statistics were calculated by group for all pharmacokinetic parameters. Analysis of variance (ANOVA) was performed using type III sums of squares for all pharmacokinetic parameters, excluding $t_{\text {max }}$. ANOVA was conducted on both $\log$ scale and original scale for $\mathrm{AUC}_{\infty}$ and $\mathrm{C}_{\max }$, and only on original scale for the other parameters. Following ANOVA, comparison between each of the three renal impairment groups and the normal renal function group was performed using Fisher's least significant difference test. For $\mathrm{t}_{\max }$, the Kruskal-Wallis test was used, followed by the Wilcoxon rank-sum test, to make comparisons between each of the three renal impairment groups and the normal renal function group.

Demographic characteristics were assessed using descriptive statistics, as were safety data (AEs, clinical laboratory measurements, vital signs, and physical examination and ECG findings). Demographic data among the four groups were compared using one-way ANOVA (for continuous variables) or the Cochran-Mantel-Haenszel test (for nominal categorical data).

\section{Results \\ Demographics}

In total, 34 participants received prucalopride and completed the study. All 34 participants had evaluable plasma and urine pharmacokinetic profiles and were included in the pharmacokinetic analysis. Of these, ten had normal renal function, eight had mild renal impairment, seven had moderate renal impairment, and nine had severe renal impairment. Demographic characteristics and disease characteristics are shown in Table 1. The mean age of the overall population was 59 years; 19 participants were men and 15 were women. There were no clinically significant demographic differences among the renal impairment groups.

\section{Pharmacokinetic results}

The overall absorption profile of prucalopride following a single $2 \mathrm{mg}$ oral dose was unaffected by the degree of renal impairment (Figure 1). In all groups, mean $\mathrm{t}_{\max }$ was approximately 3 hours, and there was no statistically significant difference in $\mathrm{t}_{\max }$ between groups (Table $2, P>0.5$ for all comparisons). $\mathrm{C}_{\max }$ was approximately $4 \mathrm{ng} / \mathrm{mL}$ in participants with normal renal function and in those with mild or moderate renal impairment but slightly higher in patients with severe renal impairment. However, there was 
Table I Baseline demographics and disease characteristics of all enrolled patients

\begin{tabular}{|c|c|c|c|c|}
\hline & $\begin{array}{l}\text { Normal renal function } \\
(N=10)\end{array}$ & $\begin{array}{l}\text { Mild renal impairment } \\
(\mathrm{N}=\mathbf{8})\end{array}$ & $\begin{array}{l}\text { Moderate renal impairment } \\
(\mathrm{N}=7)\end{array}$ & $\begin{array}{l}\text { Severe renal impairment } \\
(N=9)\end{array}$ \\
\hline \multicolumn{5}{|l|}{ Sex, N } \\
\hline Men/women & $5 / 5$ & $6 / 2$ & $5 / 2$ & $3 / 6$ \\
\hline \multicolumn{5}{|l|}{ Age, years } \\
\hline Mean & 59 & 63 & 63 & 52 \\
\hline (Range) & $(52-68)$ & $(46-74)$ & $(43-69)$ & $(45-59)$ \\
\hline \multicolumn{5}{|l|}{ Weight, kg } \\
\hline Mean & 70.3 & 78.2 & 90.1 & 75.3 \\
\hline (Range) & $(58 .|-9| .2)$ & $(54.9-107.5)$ & $(68.9-134.5)$ & (56.7-98.9) \\
\hline \multicolumn{5}{|l|}{ Height, cm } \\
\hline Mean & 168 & 174 & 172 & 167 \\
\hline (Range) & $(158-183)$ & $(160-183)$ & $(163-188)$ & $(155-180)$ \\
\hline \multicolumn{5}{|l|}{ Race, N } \\
\hline Caucasian & 6 & 4 & 4 & 0 \\
\hline Black & 2 & 4 & 3 & 9 \\
\hline Oriental & 2 & 0 & 0 & 0 \\
\hline \multicolumn{5}{|c|}{ Creatinine clearance, $\mathrm{mL} / \mathrm{min}$} \\
\hline Mean & 104 & 63 & 40 & 18 \\
\hline (Range) & $(86-123)$ & $(50-74)$ & $(25-49)$ & $(\mathrm{II}-24)$ \\
\hline
\end{tabular}

no statistically significant difference in $\mathrm{C}_{\text {max }}$ between patients with renal impairment and those with normal renal function ( $P>0.1$ for all comparisons; Table 2).

There were no statistically significant differences in $\mathrm{AUC}_{\infty}$ and $\mathrm{t}_{1 / 2}$ between participants with mild renal impairment and those with normal renal function (Table 2). However, a significantly higher systemic exposure and slower elimination of prucalopride was seen in patients with moderate or severe renal impairment than in participants with normal

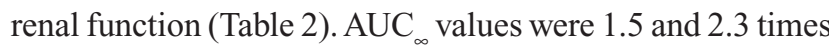
higher $(P=0.002$ and $P<0.001)$ in patients with moderate and severe renal impairment, respectively, than in those with normal renal function. In addition, mean $t_{1 / 2}$ increased from 29.9 hours (normal renal function) to 42.5 hours and 46.9 hours $(P=0.002$ and $P<0.001)$ in moderate and severe renal impairment, respectively (Table 2 ).

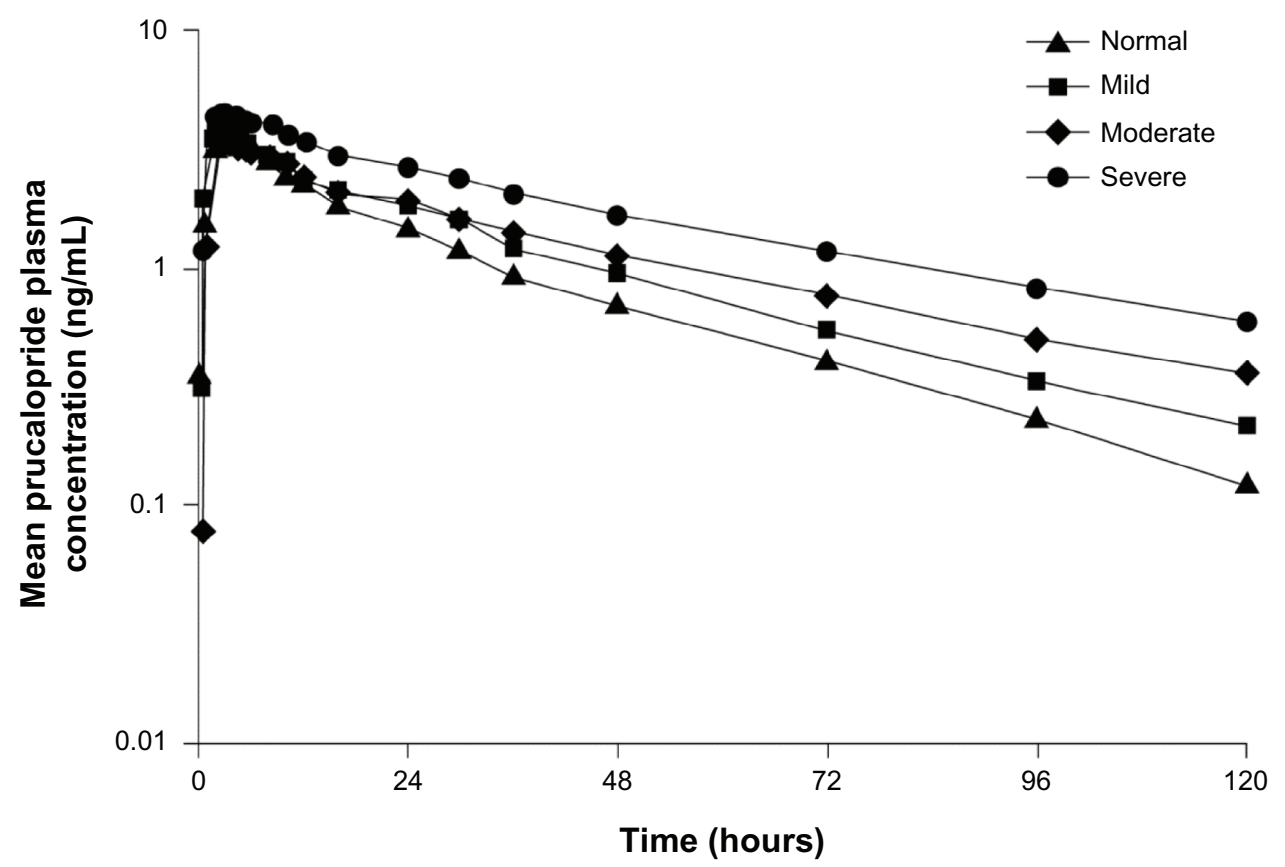

Figure I Mean plasma concentration-time profiles of prucalopride by renal function group after a single oral $2 \mathrm{mg}$ dose.

Notes: Renal status: normal (creatinine clearance $\left.\geq 80 \mathrm{~mL} / \mathrm{min} / 1.73 \mathrm{~m}^{2}\right)$, mild impairment $\left.(50-79 \mathrm{~mL} / \mathrm{min} / \mathrm{l} .73 \mathrm{~m})^{2}\right)$, moderate impairment $\left(25-49 \mathrm{~mL} / \mathrm{min} / 1.73 \mathrm{~m}{ }^{2}\right)$, and severe impairment $\left(\leq 24 \mathrm{~mL} / \mathrm{min} / 1.73 \mathrm{~m}^{2}\right)$. 
Table 2 Plasma and urinary pharmacokinetic parameters following a single oral dose of prucalopride $2 \mathrm{mg}$

\begin{tabular}{|c|c|c|c|c|c|}
\hline $\begin{array}{l}\text { Parameter, } \\
\text { mean } \pm S D\end{array}$ & $\begin{array}{l}\text { Normal renal } \\
\text { function } \\
(\mathrm{N}=10)\end{array}$ & $\begin{array}{l}\text { Mild renal } \\
\text { impairment } \\
(\mathbf{N}=\mathbf{8})\end{array}$ & $\begin{array}{l}\text { Moderate renal } \\
\text { impairment } \\
(\mathbf{N}=7)\end{array}$ & $\begin{array}{l}\text { Severe renal } \\
\text { impairment } \\
(\mathbf{N}=9)\end{array}$ & $\begin{array}{l}P \text { value for overall } \\
\text { comparison }^{\mathrm{a}} \\
(\mathrm{N}=34)\end{array}$ \\
\hline $\mathrm{C}_{\max }, \mathrm{ng} / \mathrm{mL}$ & $4.05 \pm 1.04$ & $4.17 \pm 0.98$ & $3.77 \pm 0.76$ & $5.12 \pm 1.57$ & 0.253 \\
\hline$P$ value vs normal ${ }^{b}$ & - & 0.783 & 0.696 & 0.111 & - \\
\hline$t_{\text {max }}, h$ & $3.2 \pm 1.1$ & $3.0 \pm 0.8$ & $3.2 \pm 0.9$ & $2.8 \pm 1.1$ & 0.805 \\
\hline$P$ value vs normal ${ }^{b}$ & - & $>0.999$ & 0.776 & 0.523 & - \\
\hline$A \cup C_{\infty}, \mathrm{ng} \cdot \mathrm{h} / \mathrm{mL}$ & $109 \pm 15$ & $136 \pm 27$ & $165 \pm 48$ & $25 I \pm 67$ & $<0.001$ \\
\hline$P$ value vs normal ${ }^{b}$ & - & 0.065 & 0.002 & $<0.00 \mathrm{I}$ & - \\
\hline$t_{1 / 2}$, hours & $29.9 \pm 5.7$ & $33.7 \pm 5.4$ & $42.5 \pm 10.2$ & $46.9 \pm 8.0$ & $<0.001$ \\
\hline$P$ value vs normal ${ }^{b}$ & - & 0.286 & 0.002 & $<0.001$ & - \\
\hline CL/F, L/hour & $18.7 \pm 3.0$ & $15.2 \pm 3.2$ & $13.0 \pm 3.7$ & $8.5 \pm 2.6$ & $<0.001$ \\
\hline$P$ value vs normal ${ }^{b}$ & - & 0.025 & $<0.001$ & $<0.001$ & - \\
\hline PPB, \% & $32 \pm 6.1$ & $31 \pm 2.2$ & $31 \pm 1.8$ & $28 \pm 1.8$ & 0.112 \\
\hline$P$ value vs normal ${ }^{b}$ & - & 0.683 & 0.643 & 0.023 & - \\
\hline $\mathrm{Ae}_{120 \mathrm{~h}}, \mathrm{mg}$ & $124 \pm 0.09$ & $1.02 \pm 0.24$ & $0.80 \pm 0.13$ & $0.53 \pm 0.19$ & $<0.001$ \\
\hline$P$ value vs normal ${ }^{b}$ & - & 0.011 & $<0.00 \mathrm{I}$ & $<0.00 \mathrm{I}$ & - \\
\hline $\mathrm{Fe}_{120 \mathrm{~h}}$ & $0.62 \pm 0.04$ & $0.51 \pm 0.12$ & $0.40 \pm 0.07$ & $0.26 \pm 0.09$ & $<0.001$ \\
\hline$P$ value vs normal ${ }^{b}$ & - & 0.011 & $<0.001$ & $<0.001$ & - \\
\hline $\mathrm{CL}_{\mathrm{R}}$, L/hour & $12.2 \pm 1.8$ & $8.5 \pm 2.7$ & $5.9 \pm 1.3$ & $2.6 \pm 0.8$ & $<0.001$ \\
\hline$P$ value vs normal ${ }^{b}$ & - & $<0.00 \mathrm{I}$ & $<0.00 \mathrm{I}$ & $<0.001$ & - \\
\hline
\end{tabular}

Notes: ${ }^{a} P$ values for overall comparison among the four groups; ${ }^{b} P$ values for pair-wise comparisons between each renal impairment group and the normal renal function group.

Abbreviations: $\mathrm{Ae}_{120 \mathrm{~h}}$, cumulative amount of prucalopride excreted in the urine from 0 to $\mathrm{I} 20$ hours; AUC , area under the plasma concentration-time curve from time zero to infinity; $\mathrm{CL} / \mathrm{F}$, apparent total body clearance; $\mathrm{CL}_{\mathrm{R}}$, renal clearance; $\mathrm{C}_{\max }$, maximum plasma concentration; $\mathrm{Fe}_{120}$, cumulative fraction of the dose excreted unchanged in urine from time 0 to 120 hours; PPB, plasma protein binding; SD, standard deviation; $t_{1 / 2}$, terminal half-life; $t_{\max }$, time to $C_{\max }$.

Overall, there was no statistically significant difference in PPB among the four groups $(P=0.112)$. Pair-wise comparison with the normal group showed a statistically significant difference in PPB between patients with severe renal impairment and participants with normal renal function ( $28 \%$ vs $32 \%$, respectively; $P=0.023$; Table 2 ).

$\mathrm{CL} / \mathrm{F}$ and $\mathrm{CL}_{\mathrm{R}}$ were both statistically significantly lower in all renal impairment groups compared with the normal renal function group (Table 2). The proportion of $\mathrm{CL} / \mathrm{F}$ that was accounted for by $\mathrm{CL}_{\mathrm{R}}$ decreased from $65 \%$ in participants with normal renal function to $56 \%, 45 \%$, and $30 \%$ in those with mild, moderate, and severe renal impairment, respectively. Accordingly, $\mathrm{Fe}_{120 \mathrm{~h}}$ decreased from $62 \%$ of the dose in participants with normal renal function to $51 \%(P=0.011)$, 40\% $(P<0.001)$, and 26\% $(P<0.001)$ in those with mild, moderate, and severe renal impairment, respectively. Passive $\left(\mathrm{CL}_{\mathrm{gfr}}\right)$ and active $\left(\mathrm{CL}_{\mathrm{act}}\right)$ renal excretion accounted for approximately one-third and two-thirds of total renal clearance, respectively, in all groups (Table 3). Increasing degrees of renal impairment were associated with reductions in both passive and active renal excretion. Decreasing $\mathrm{CL}_{\mathrm{CR}}$ was significantly correlated with decreasing $\mathrm{CL} / \mathrm{F}\left(\mathrm{R}^{2}=0.607\right.$; $P<0.001$; Figure 2A) and $\mathrm{CL}_{\mathrm{R}}\left(\mathrm{R}^{2}=0.837 ; P<0.001\right.$; Figure 2B). No differences in the relationships between $\mathrm{CL}_{\mathrm{CR}}$ and $\mathrm{CL} / \mathrm{F}$ or $\mathrm{CL}_{\mathrm{R}}$ were observed between men and women, or between different races (data not shown).

Table 3 Renal clearance parameters following a single oral dose of prucalopride $2 \mathrm{mg}$

\begin{tabular}{|c|c|c|c|c|}
\hline $\begin{array}{l}\text { Parameter, } \\
\text { mean } \pm \text { SD }\end{array}$ & $\begin{array}{l}\text { Normal renal function } \\
(N=10)\end{array}$ & $\begin{array}{l}\text { Mild renal impairment } \\
(\mathrm{N}=8)\end{array}$ & $\begin{array}{l}\text { Moderate renal impairment } \\
(\mathbf{N}=7)\end{array}$ & $\begin{array}{l}\text { Severe renal impairment } \\
(N=9)\end{array}$ \\
\hline $\mathrm{CL}_{\text {gfr }}$, L/hour & $4.2 \pm 0.5$ & $2.6 \pm 0.4$ & $1.7 \pm 0.3$ & $0.8 \pm 0.2$ \\
\hline $\mathrm{CL}_{\text {act }}$, L/hour & $8.0 \pm 1.6$ & $5.9 \pm 2.6$ & $4.2 \pm 1.2$ & $1.8 \pm 0.8$ \\
\hline $\mathrm{CL}_{\mathrm{grr}} / \mathrm{CL}_{\mathrm{R}}$ & $0.35 \pm 0.04$ & $0.33 \pm 0.10$ & $0.29 \pm 0.08$ & $0.32 \pm 0.08$ \\
\hline $\mathrm{CL}_{\text {act }} / \mathrm{CL}_{\mathrm{R}}$ & $0.65 \pm 0.04$ & $0.67 \pm 0.10$ & $0.71 \pm 0.08$ & $0.68 \pm 0.08$ \\
\hline $\mathrm{CL}_{\mathrm{grr}} / \mathrm{CL} / \mathrm{F}$ & $0.23 \pm 0.03$ & $0.18 \pm 0.04$ & $0.14 \pm 0.05$ & $0.10 \pm 0.03$ \\
\hline $\mathrm{CL}_{\mathrm{act}} / \mathrm{CL} / \mathrm{F}$ & $0.43 \pm 0.04$ & $0.38 \pm 0.13$ & $0.33 \pm 0.06$ & $0.22 \pm 0.09$ \\
\hline
\end{tabular}

Abbreviations: $\mathrm{CL}_{\text {act; }}$, active renal secretion rate; $\mathrm{CL}_{\text {act }} / \mathrm{CL} / \mathrm{F}$, fraction of apparent total clearance due to active renal secretion; $\mathrm{CL}_{\text {act }} / \mathrm{CL}_{\mathrm{R}}$, fraction of renal clearance due to active renal secretion; $\mathrm{CL}_{\mathrm{gfr}}$ glomerular filtration rate of prucalopride; $\mathrm{CL}_{g \mathrm{rt}} / \mathrm{CL}_{\mathrm{R}}$, fraction of renal clearance due to glomerular filtration; $\mathrm{CL} \mathrm{gfr} / \mathrm{CL} / \mathrm{F}$, fraction of apparent total clearance due to glomerular filtration rate; SD, standard deviation. 

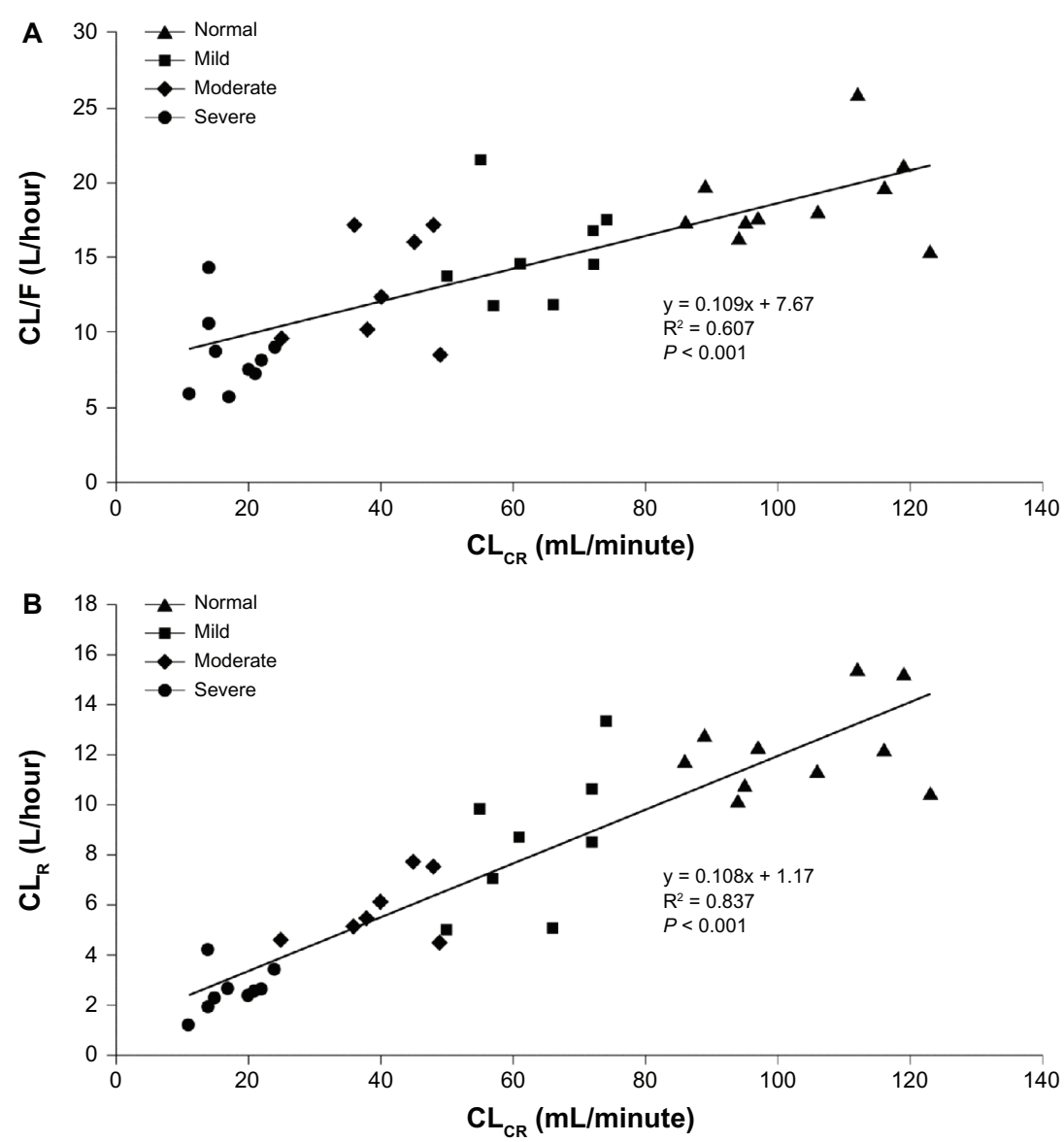

Figure 2 Correlation between creatinine clearance $\left(\mathrm{CL}_{\mathrm{CR}}\right)$ and $(\mathbf{A})$ apparent total body clearance $(\mathrm{CL} / \mathrm{F})$ and $(\mathbf{B})$ renal clearance $\left(\mathrm{CL}_{\mathrm{R}}\right)$.

Notes: Renal status: normal (creatinine clearance $\left.\geq 80 \mathrm{~mL} / \mathrm{min} / 1.73 \mathrm{~m}^{2}\right)$, mild impairment $\left(50-79 \mathrm{~mL} / \mathrm{min} / 1.73 \mathrm{~m}{ }^{2}\right)$, $\mathrm{moderate}$ impairment $\left(25-49 \mathrm{~mL} / \mathrm{min} / 1.73 \mathrm{~m}{ }^{2}\right)$, and severe impairment $\left(\leq 24 \mathrm{~mL} / \mathrm{min} / 1.73 \mathrm{~m}^{2}\right)$.

\section{Safety and tolerability}

AE profiles were similar in the normal renal function group and all three renal impairment groups. Most individuals (32 patients, 94\%) in this study experienced at least one AE following single-dose administration of prucalopride. The most common AEs were diarrhea ( $85 \%$ of patients), abdominal pain (35\%), headache $(29 \%)$, and nausea (18\%). All participants who experienced nausea had some degree of renal impairment. All but three AEs were mild or moderate in severity; the only AEs classified as severe were two cases of diarrhea and one of nausea. Two cases of diarrhea, one case of nausea, and one case of myalgia were categorized as being very likely to be related to the study medication. The majority of other AEs (including all cases of abdominal pain and the remaining cases of diarrhea) were categorized as probably related to the study medication.

There were no deaths and no serious AEs in the study and no withdrawals from the study because of AEs. Furthermore, no safety concerns were identified from results of clinical laboratory investigations, vital signs, or ECG or physical examination findings. There were no clinically significant changes from baseline in blood pressure or mean heart rate and no rhythm disorder AEs. Observed increases in corrected QT intervals were not clinically significant and appeared to reflect normal variations.

\section{Discussion}

This open-label single-dose study evaluated the pharmacokinetics of prucalopride in patients with different degrees of renal impairment compared with individuals with normal renal function. The pharmacokinetics of prucalopride observed in participants with normal renal function in the present study are consistent with those reported in other studies, ${ }^{1,2,6}$ which have found that after a single oral dose of prucalopride $2 \mathrm{mg}$, $\mathrm{C}_{\max }$ is reached within $2-3$ hours, $\mathrm{AUC}_{\infty}$ is approximately $100-110 \mathrm{ng} \cdot \mathrm{h} / \mathrm{mL}$, and $\mathrm{t}_{1 / 2}$ is approximately 1 day. The results of the present study also confirm that, in patients with normal renal function, prucalopride is predominantly excreted in the urine ( $62 \%$ of the administered dose). 
The present study shows that renal function does not have any substantial effect on the absorption profile of prucalopride. $\mathrm{C}_{\max }$ was reached within approximately 3 hours in individuals with varying degrees of renal impairment, and there were no statistically significant differences between any of the renal impairment groups and the normal renal function group. However, as anticipated from the predominantly renal elimination of prucalopride in individuals with normal renal function, the overall exposure to prucalopride increased with the severity of renal impairment. The increase in exposure was modest in those with mild or moderate renal impairment compared with healthy individuals; $\mathrm{AUC}_{\infty}$ was 1.3 times higher in patients with mild renal impairment and 1.5 times higher in those with moderate impairment, relative to patients with normal renal function. In patients with severe renal impairment, the effect was more pronounced, with $\mathrm{AUC}_{\infty}$ being 2.3 times higher than in individuals with normal renal function.

The $t_{1 / 2}$ of prucalopride was also influenced by renal impairment, being significantly longer in patients with moderate (42.5 hours) or severe (46.9 hours) renal impairment than in those with normal renal function (29.9 hours). The PPB was slightly lower in the severe renal impairment group $(28 \%)$ than in the other groups $(31 \%-32 \%)$. Although the pair-wise comparison of PPB between those with normal renal function and those with severe renal impairment was found to be statistically significant (uncorrected for multiplicity), the difference between the groups was small and considered unlikely to be of clinical relevance, particularly because the PPB of prucalopride is low.

As expected, renal clearance and apparent total clearance were reduced in proportion to the degree of renal impairment, the effect on renal clearance being the most pronounced. Whereas renal clearance of prucalopride accounted for $65 \%$ of its overall clearance in the normal renal function group, this proportion was reduced to $30 \%$ in patients with severe renal impairment. In the group with normal renal function, passive and active renal excretion represented one-third and two-thirds of total renal excretion, respectively. These ratios remained of the same order in the various renal impairment groups, indicating that the effect of renal impairment was similar on passive and active secretion.

Although prucalopride is currently only licensed for the treatment of women, this study included both male and female participants. There were no apparent differences between men and women in the correlation between $\mathrm{CL}_{\mathrm{R}}$, $\mathrm{CL} / \mathrm{F}$, and $\mathrm{CL}_{\mathrm{CR}}$. Furthermore, there was no clear effect of race on this correlation, despite the imbalance of ethnicities in the different renal impairment groups (ie, only black participants were included in the group with severe renal impairment). This has also been confirmed in a previous population pharmacokinetic analysis including healthy participants, healthy elderly participants, patients with renal impairment, and patients with chronic constipation, which demonstrated that sex and race had no effect on the apparent total clearance of prucalopride. ${ }^{2}$

Most of the participants in this study reported at least one AE. Although only two cases were classified as being very likely to be related to the study medication, $85 \%$ of participants experienced diarrhea of at least mild severity that was considered at least probably related to the study drug. However, the severity of these AEs was within an acceptable range and was consistent with the prokinetic nature of prucalopride. In addition, the severity of the AEs was unaffected by renal impairment status.

Phase III studies have shown that treatment with prucalopride $2 \mathrm{mg}$ once daily is associated with an increased frequency of spontaneous complete bowel movements in adults with chronic constipation. ${ }^{3-5}$ In the Phase III studies, prucalopride was well tolerated, even at twice the recommended daily dose. The present study shows that exposure to prucalopride in individuals with mild or moderate renal impairment is increased by $50 \%$ or less compared with those with normal renal function. Given the acceptable safety profile of prucalopride $4 \mathrm{mg}$ once daily in Phase III trials, this increased exposure is unlikely to result in poor tolerability; therefore, prucalopride can be used at the recommended dose of $2 \mathrm{mg}$ once daily in these patients. However, clinically meaningful increases in exposure were seen in patients with severe renal impairment. A dose reduction to $1 \mathrm{mg}$ once daily is therefore recommended in this patient group.

\section{Acknowledgments}

Clinical research was funded by the sponsors, Janssen Pharmaceutica NV and Shire-Movetis NV. Under the direction of the authors, Catherine Hill, $\mathrm{PhD}$, an employee of PharmaGenesis ${ }^{\mathrm{TM}}$ London, provided writing assistance for this publication. Editorial assistance in formatting, proofreading, copy editing, and fact checking was provided by Oxford PharmaGenesis ${ }^{\mathrm{TM}}$ Ltd. Slavka Baronikova PhD from Shire-Movetis NV also reviewed and edited the manuscript for scientific accuracy. Shire-Movetis NV provided funding to Oxford PharmaGenesis ${ }^{\mathrm{TM}} \mathrm{Ltd}$, for support in writing and editing this manuscript. Although the sponsor was involved in the design, collection, analysis, interpretation, and fact checking of information, the content of this manuscript, 
the ultimate interpretation, and the decision to submit it for publication in Drug Design, Development and Therapy was made by the authors independently. Resolor is a CTM registered trademark of Shire-Movetis NV.

\section{Disclosures}

EM and TV are employees of Janssen Research and Development, Janssen Pharmaceutica NV in Belgium. RK and LV are employees of Shire-Movetis NV in Belgium and own stocks in Shire. VV is a consultant for Shire-Movetis. WBS received a grant to the New Orleans Center for Clinical Research for participation in this study.

\section{References}

1. Resolor (prucalopride). Summary of product characteristics. Available from: http://www.ema.europa.eu/docs/en_GB/document_library/ EPAR_-_Product_Information/human/001012/WC500053998.pdf. Accessed March 26, 2012.

2. Frampton JE. Prucalopride. Drugs. 2009;69(17):2463-2476.

3. Camilleri M, Kerstens R, Rykx A, Vandeplassche L. A placebo-controlled trial of prucalopride for severe chronic constipation. $N$ Engl J Med. 2008;358(22):2344-2354.
4. Tack J, van Outryve M, Beyens G, Kerstens R, Vandeplassche L. Prucalopride (Resolor) in the treatment of severe chronic constipation in patients dissatisfied with laxatives. Gut. 2009;58(3):357-365.

5. Quigley EM, Vandeplassche L, Kerstens R, Ausma J. Clinical trial: the efficacy, impact on quality of life, and safety and tolerability of prucalopride in severe chronic constipation - a 12-week, randomized, double-blind, placebo-controlled study. Aliment Pharmacol Ther. 2009; 29(3):315-328.

6. Van de Velde V, Ausma J, Vandeplassche L. Pharmacokinetics of prucalopride (Resolor ${ }^{\circledR}$ ) in man. Gut. 2008;Suppl 2:A282 (abstract).

7. Movetis. Prucalopride subjects with renal impairment. In: ClinicalTrials. gov [website on the Internet]. Bethesda, MD: US National Library of Medicine; 2012 [updated August 27, 2012]. Available from: http://clinicaltrials.gov/ct2/show/NCT01674192. NLM identifier: NCT01674192. Accessed September 22, 2012.

8. European Medicines Agency (EMEA). Note for Guidance on Good Clinical Practice. ICH harmonized tripartite guideline, CPMP/ ICH/135/95. London: EMEA; 2002. Available from: http://www.emea. europa.eu/pdfs/human/ich/013595en.pdf. Accessed June 11, 2012.

9. World Medical Association (WMA). WMA Declaration of Helsinki: Ethical Principles for Medical Research Involving Human Subjects. Available from: http://www.wma.net/en/30publications/10policies/b3/. Accessed August 12, 2009.

\section{Publish your work in this journal}

Drug Design, Development and Therapy is an international, peerreviewed open-access journal that spans the spectrum of drug design and development through to clinical applications. Clinical outcomes, patient safety, and programs for the development and effective, safe, and sustained use of medicines are a feature of the journal, which has also been accepted for indexing on PubMed Central. The manuscript management system is completely online and includes a very quick and fair peer-review system, which is all easy to use. Visit http://www.dovepress.com/testimonials.php to read real quotes from published authors.

Submit your manuscript here: http://www.dovepress.com/drug-design-development-and-therapy-journal 